\title{
A Two Stage Methodology for Siting and Sizing of DG for Minimum Loss in Radial Distribution System using RCGA
}

\author{
Dr.M.Padma Lalitha \\ IEEE Member \\ Professor \& HOD \\ Dept. of E.E.E \\ University, \\ A.I.T.S, Rajampet, A.P.
}

\author{
Dr.V.C. Veera Reddy \\ Professor \& HOD \\ Dept. of E.E.E \\ S.V.U.C.E,S.V.University, \\ Tirupathi, A.P
}

\author{
N.Sivarami Reddy \\ Professor \& HOD \\ Dept. of Mech.Engg., \\ A.I.T.S, Rajampet, A.P.
}

\author{
V.Usha Redddy \\ Assistant Professor \\ Dept. of E.E.E \\ S.V.U.C.E,S.V. \\ Tirupathi, A.P.
}

\begin{abstract}
This paper presents a new methodology using Real Coded Genetic Algorithm (RCGA) for the placement of Distributed Generators(DG) in the radial distribution systems to reduce the real power losses and to improve the voltage profile. A two-stage methodology is used for the optimal DG placement. In the first stage, single DG placement algorithm is used to find the optimal DG locations and in the second stage, Real Coded Genetic Algorithm is used to find the size of the DGs corresponding to maximum loss reduction. The proposed method is tested on standard IEEE 33 bus test system and the results are presented.
\end{abstract}

Keywords: DG placement, Real Coded Genetic Algorithm, loss reduction, radial distribution system.

\section{INTRODUCTION}

Distributed or dispersed generation (DG) or embedded generation (EG) is small-scale power generation that is usually connected to or embedded in the distribution system. The term DG also implies the use of any modular technology that is sited throughout a utility's service area (interconnected to the distribution or sub-transmission system) to lower the cost of service [1]. The benefits of DG are numerous [2,3] and the reasons for implementing DGs are an energy efficiency or rational use of energy, deregulation or competition policy, diversification of energy sources, availability of modular generating plant, ease of finding sites for smaller generators, shorter construction times and lower capital costs of smaller plants and proximity of the generation plant to heavy loads, which reduces transmission costs. Also it is accepted by many countries that the reduction in gaseous emissions (mainly $\mathrm{CO}_{2}$ ) offered by DGs is major legal driver for DG implementation [4].

The distribution planning problem is to identify a combination of expansion projects that satisfy load growth constraints without violating any system constraints such as equipment overloading [5]. Distribution network planning is to identify the least cost network investment that satisfies load growth requirements without violating any system and operational constraints. Due to their high efficiency, small size, low investment cost, modularity and ability to exploit renewable energy sources, are increasingly becoming an attractive alternative to network reinforcement and expansion..Numerous studies used different approaches to evaluate the benefits from DGs to a network in the form of loss reduction, loading level reduction [6-8].

Naresh Acharya et al suggested a heuristic method in [9] to select appropriate location and to calculate DG size for minimum real power losses. Though the method is effective in selecting location, it requires more computational efforts. The optimal value of DG for minimum system losses is calculated at each bus. Placing the calculated DG size for the buses one by one, corresponding system losses are calculated and compared to decide the appropriate location. This method is used to calculate DG size based on approximate loss formula may lead to an inappropriate solution.

In the literature, genetic algorithm has been applied to DG placement [10-12].In all these works both sizing and location of DGs are determined by GA. In this paper, the optimal locations of distributed generators are identified based on the single DG placement algorithm and a GA based technique which takes the number and location of DGs as input has been developed to determine the optimal size(s) of DG to minimize real power losses in distribution systems. The advantages of relieving GA from determination of locations of DGs are improved convergence characteristics and less computation time. Voltage and thermal constraints are considered. The effectiveness of the proposed algorithm was validated using 33-Bus Distribution System [13].To test the effectiveness of proposed method, results are compared with the results of an analytical method reported in [14]. It is observed that the proposed method yield more savings as compared to analytical method.

\section{THEORETICAL BACKGROUND}

The total $\stackrel{2}{I} \mathrm{R}$ loss $\left(\mathrm{P}_{\mathrm{L}}\right)$ in a distribution system having $n$ number of branches is given by:

$$
P_{L t}=\sum_{i=1}^{n} I_{i}^{2} R_{i}
$$

Here $I_{i}$ is the magnitude of the branch current and $R_{i}$ is the resistance of the $i$ branch respectively. The branch current can be obtained from the load flow solution. The branch current has two components, active component $(I)$ and reactive component $(I)$. The loss associated with the active and reactive components of branch currents can be written as: 


$$
\begin{aligned}
& P_{L a}=\sum_{i=1}^{n} I_{a i}^{2} R_{i} \\
& P_{L r}=\sum_{i=1}^{n} I_{r i}^{2} R_{i}
\end{aligned}
$$

Note that for a given configuration of a single-source radial network, the loss $\mathrm{P}_{\mathrm{La}}$ associated with the active component of branch currents cannot be minimized because all active power must be supplied by the source at the root bus. However by placing DGs, the active component of branch currents are compensated and losses due to active component of branch current is reduced. This paper presents a method that minimizes the loss due to the active component of the branch current by optimally placing the DGs and thereby reduces the total loss in the distribution system. A two stage methodology is applied here. In the first stage optimum location of the DGs are determined by using an analytical approach and in the second stage RCGA is used to determine sizes of the DGs for maximum real loss reduction.

\section{IDENTIFICATION OF OPTIMAL DG LOCATIONS -STAGE-I}

\subsection{Single DG Placement Algorithm}

This algorithm determines the optimal size and location of DG units that should be placed in the system where maximum loss saving occurs. First optimum sizes of DG units for all nodes are determined for base case and best one is chosen based on the maximum loss saving. If single DG placement is required this process is stopped here. This process is repeated if multiple DG locations are required by modifying the base system by inserting a DG unit into the system one-by-one.

\subsection{Single DG Placement Algorithm}

Assume that a single-source radial distribution system with $n$ branches and a DG is to be placed at bus $m$ and $\alpha$ be a set of branches connected between the source and bus m. As referred to Fig. 1, assume that a DG is placed at bus 23, the set of $\alpha$ consists of branches $1,2,3,4,5,16,17,18,19,20,21$ and 22 . The DG produces active current $\mathrm{I}_{\mathrm{DG}}$, and for a radial network it changes only the active component of current of branch set $\alpha$. The current of other branches $(\notin=\alpha)$ are unaffected by the DG. Thus the new active current $\mathrm{I}_{a i}^{n e w}$ of the $i^{\text {th }}$ branch is given by

$$
\mathrm{I}_{a i}^{n e w}=\mathrm{I}_{\mathrm{ai}}+\mathrm{D}_{\mathrm{i}} \mathrm{I}_{\mathrm{DG}}
$$

where $D_{i}=1$; if branch $i \in \alpha$

$$
=0 \text {; otherwise }
$$

The loss $\mathrm{P}_{\mathrm{La}}{ }^{\text {com }}$ associated with the active component of branch currents in the compensated currents in the compensated system (when the DG is connected) can be written as

$$
P_{L a}^{c o m}=\sum_{i=1}^{n}\left(I_{a i}+D_{i} I_{D G}\right)^{2} R_{i}
$$

The loss saving $\mathrm{S}$ is the difference between equation 2 and 5 and is given by

$$
\begin{aligned}
& S=P_{L a}-P_{L a}^{c o m} \\
& =-\sum_{i=1}^{n}\left(2 D_{i} I_{a i} I_{D G}+D_{D G} I_{c}^{2}\right) R_{i}
\end{aligned}
$$

The DG current $\mathrm{I}_{\mathrm{DG}}$ that provides the maximum loss saving can be obtained from

$$
\frac{\partial S}{\partial I_{D G}}=-2 \sum_{i=1}^{n}\left(D_{i} I_{a i}+D_{i} I_{D G}\right) R_{i}=0 \text { (7) }
$$

Thus the DG current for the maximum loss saving is

$$
I_{D G}=-\frac{\sum_{i=1}^{n} D_{i} I_{a i} R_{i}}{\sum_{i=1}^{n} D_{i} R_{i}}=-\frac{\sum_{i \in \alpha} I_{a i} R_{i}}{\sum_{i \in \alpha} R_{i}}
$$

The corresponding DG size is

$$
\mathrm{P}_{\mathrm{DG}}=\mathrm{V}_{\mathrm{m}} \mathrm{I}_{\mathrm{DG}}
$$

$\mathrm{V}_{\mathrm{m}}$ is the voltage magnitude of the bus $m$. The optimum size of DG for each bus is determined using eqn (9). Then possible loss saving for each DG is determined by using eqn (6).The DG with highest loss saving is identified as candidate location for single Dg placement. When the candidate bus is identified and DG is placed, the above technique can also be used to identify the next and subsequent bus to be compensated for loss reduction.

\subsection{Algorithm}

Step 1: Conduct load flow analysis for the original system .

Step 2: Calculate the DG currents $\left(\mathrm{I}_{\mathrm{DG}}\right)$ and $\mathrm{DG}$ size using equations $8 \& 9$ from $i=2$ for all buses except source bus.

Step 3: Determine loss saving (S) using equation 6 , from $i=2$ for all buses except source bus.

Step 4: Identify the maximum saving and the corresponding DG size.

Step5: Modify the active load on the network and conduct the load flow again.

Step 6: Check whether the saving obtain is more than $1 \mathrm{~kW}$. If the saving is significant, go to step 2. Otherwise, go to next step.

Step 7: This bus is a candidate bus where DG is placed . Repeat the procedure until the loss is significant $\mathrm{kW})$.

Here the effect of DG placement on real power loss only is considered. The effect of DG on Reactive power loss, voltage profile and system capacity rise is neglected.

Since the DGs are added to the system one by one, the sizes obtained using single DG placement algorithm are local optima not global optimum solution. The global optimal solution is obtained if multiple DGs are simultaneously placed in the system by using genetic algorithm. This method is explained in next section. 


\section{IDENTIFICATION OF OPTIMAL DG SIZES BY REAL CODED GENETIC ALGORITHM \\ 4.1. Introduction to Genetic Algorithm}

Genetic algorithms are practical, robust optimization and search methods. Genetic algorithms were invented by Holland to mimic some of the processes of natural evolution and selection. These algorithms are different from most of the traditional optimization methods and these algorithms need design space to be converted into genetic space. A more striking difference between genetic algorithms and most of the traditional optimization methods is that GA uses a population of points at one time, in contrast to the single point approach by traditional optimization methods. The most interesting aspect of GA is that they do not require any prior knowledge of the function to be optimized and they exhibit very good performance on the majority of the problems applied.

The genetic algorithm repeatedly modifies a population of individual solutions. At each step, the genetic algorithm selects individuals at random from the current population to be parents and uses them to produce the children for the next generation. Over successive generations, the population evolves towards an optimal solution. The genetic algorithms can be used to solve a variety of optimization problems that are not well suited for standard optimization algorithms.

There are a number of different algorithms that can be applied to many domains, from data analysis to autonomous navigation [14]. These immune algorithms were inspired by works on theoretical immunology and several processes that occur within the IS. The AISs lead to the development of different techniques, each one mapping a different mechanism of the system. For examples, the Artificial Immune Networks as proposed by Farmer et al. [15], the Clonal Selection Algorithm proposed by de Castro and Von Zuben [16], and the Negative Selection Algorithm introduced by Forrest et al. [17]. Immune network models are suitable to deal with dynamic environments and optimization problems, algorithms based upon the clonal selection principle are adequate to solve optimization and scheduling problems, and the negative selection strategies are successfully applied to anomaly detection.

\subsection{Application of Genetic Algorithm to determine DG unit sizes}

After identifying the $n$ number of candidate locations using fuzzy approach, the DG sizes in all these $n$ candidate locations are obtained by using the Real Coded Genetic Algorithm (RCGA). In this proposed method, the real number encoding has been used to determine the sizes of $n$ number of DGs in the $n$ candidate locations.

Step 1: Initial population of [nop $\mathrm{x} n$ ] number of real numbers is generated randomly within the limits, where nop is the initial population size and $n$ is the number of DGs. Each row represents one possible solution to the optimal DG-sizing problem. Iteration count is set to one.

Step 2: By placing all the $n$ DGs of each chromosome at the respective candidate locations and load flow performed to find the total real power loss $\mathrm{P}_{\mathrm{L}}$. The same procedure is repeated for the nop number of chromosomes to find the total real power losses. Check voltage and thermal constraints. If constraints are not violated evaluate Fitness value.

Step 3: The population is arranged in the descending order according to their fitness values. Maximum fitness and average fitness values are calculated.

Error $=($ maximum fitness - average fitness $)$

Error is calculated using the equation (5). If this error is less than a specified tolerance then go to step 9 .

Step 4: The best chromosomes are directly copied to the next generation population to perform the elitism with a probability of $\mathrm{P}_{\mathrm{e}}$.

Step 5: Parents are selected in pairs by using the roulette wheel selection technique based on their fitness values.

Step 6: Crossover is performed using the two crossover operators. These two crossover operators are the arithmetic crossover and the heuristic crossover. A random number $r$ is generated between zero and one. If the random number $r$ is less than 0.5 then arithmetic crossover operator is used to produce the offspring, otherwise heuristic crossover operator is used to produce the offspring.

Step 7: The iteration count is incremented and whether this iteration count is greater than iteration maximum or not is checked. If it is greater than iteration count then go to step 9.

Step 8: After performing the elitism and crossover operators, the new population is generated from the old population. In this present work mutation operator is eliminated. Go to step 2 to repeat the same procedure.

Step 9: Stop the procedure and print the results.

\section{RESULTS AND DISCUSSION}

First load flow is conducted for IEEE 33 bus test system[7]. The power loss due to active component of current is $136.9836 \mathrm{~kW}$ and power loss due to reactive component of the current is $66.9252 \mathrm{~kW}$. A program is written in "MATLAB" to calculate the loss saving, DG size and location for maximum loss saving. For the first iteration the maximum loss saving is occurring at bus 6 . The candidate location for DG is bus 6 with a loss saving of $92.1751 \mathrm{~kW}$. The optimum size of DG at bus 6 is 2.4886 MW. By assuming 2.4886 MW DG is connected at bus 6 of base system and is considered as base case. Now the candidate location is bus 15 with $0.4406 \mathrm{MW}$ size and the loss saving is $11.4385 \mathrm{KW}$. This process is repeated till the loss saving is insignificant. The results are shown in Table 1. 
Table 1-Single DG placement results

\begin{tabular}{|c|c|c|c|}
\hline $\begin{array}{c}\text { iteration } \\
\text { No. }\end{array}$ & Bus No. & $\begin{array}{c}\text { DG Size } \\
\text { (MW) }\end{array}$ & $\begin{array}{c}\text { Saving } \\
\text { (KW) }\end{array}$ \\
\hline 1 & 6 & 2.4886 & 92.1751 \\
\hline 2 & 15 & 0.4406 & 11.4385 \\
\hline 3 & 25 & 0.6473 & 7.6936 \\
\hline 4 & 32 & 0.4345 & 8.1415 \\
\hline
\end{tabular}

The solution obtained above is local optimum solution but not global optimum solution. The DG sizes corresponding to global optimum solution are determined using RCGA. The candidate locations for DG placement are taken from single DG placement algorithm i.e. 6,15,25,32. With these locations, sizes of DGs are determined by using Real Coded Genetic Algorithm described in section 4. The sizes of DGs are dependent on the number of DG locations. Generally it is not possible to install many DGs in a given radial system. Here 4 cases are considered . In case I only one DG installation is assumed. In case II two DGs , in case III three DGS and in the last case four DGs are assumed to be installed. DG sizes in the four optimal locations, total real power losses before and after DG installation for four cases are given in Table 2.

Table 2: Results of IEEE 33 bus system.

\begin{tabular}{|c|c|c|c|c|c|c|c|}
\hline Case & $\begin{array}{c}\text { bus } \\
\text { locations }\end{array}$ & $\begin{array}{c}\text { DG } \\
\operatorname{sizes}(M w)\end{array}$ & $\begin{array}{c}\text { Total } \\
\text { Size(MW) }\end{array}$ & $\begin{array}{c}\text { losses before DG } \\
\text { installation } \\
(\mathrm{Kw}) \\
\end{array}$ & $\begin{array}{c}\text { loss after DG } \\
\text { installation } \\
(\mathrm{Kw}) \\
\end{array}$ & $\begin{array}{c}\text { saving(Kw } \\
)\end{array}$ & $\begin{array}{c}\text { saving/ DG } \\
\text { size }\end{array}$ \\
\hline I & 6 & 2.479 & 2.479 & \multirow{10}{*}{203.9088} & 105.0231 & 98.8857 & 39.9 \\
\hline \multirow{2}{*}{ II } & 6 & 1.950 & \multirow{2}{*}{2.5464} & & \multirow{2}{*}{89.9682} & \multirow{2}{*}{113.94} & \multirow{2}{*}{44.75} \\
\hline & 15 & 0.57 & & & & & \\
\hline \multirow{3}{*}{ III } & 6 & 1.74 & \multirow{3}{*}{3.0726} & & \multirow{3}{*}{79.2516} & \multirow{3}{*}{124.657} & \multirow{3}{*}{40.571} \\
\hline & 15 & 0.57 & & & & & \\
\hline & 25 & 0.7626 & & & & & \\
\hline \multirow{4}{*}{ IV } & 6 & 1.018 & \multirow{4}{*}{$3 . .009$} & & \multirow{4}{*}{66.5892} & \multirow{4}{*}{137.32} & \multirow{4}{*}{45.63} \\
\hline & 15 & 0.5695 & & & & & \\
\hline & 25 & 0.7626 & & & & & \\
\hline & 32 & 0.650 & & & & & \\
\hline
\end{tabular}

The last column in Table 2 represents the saving in $\mathrm{Kw}$ for 1 MW DG installation. The case with greater ratio is economical. The case IV is economically best than other cases since it has highest ratio and the saving is also maximum. As the number of DGs installed is increasing the saving is also increasing. In case 4 maximum saving is achieved but the number of DGs is four. Though the ratio of DG size to saving is minimum of all cases which represent optimum solution but the number of DGs involved is four so it is not economical by considering the cost of installation of 4 DGs. But in view of reliability, quality and future expansion of the system it is the best solution.

Table 3 shows the minimum voltage and \% improvement in minimum voltage compared to base case for all the four cases. In all the cases voltage profile is improved and the improvement is very significant in case 4 . The voltage profile for all cases is shown in Fig.1.
Table 3: Voltage improvement with DG placement

\begin{tabular}{|c|c|c|c|}
\hline $\begin{array}{c}\text { case } \\
\text { No. }\end{array}$ & Bus No. & $\begin{array}{c}\text { Min } \\
\text { Voltage }\end{array}$ & \% change \\
\hline $\begin{array}{c}\text { Base } \\
\text { case }\end{array}$ & 18 & 0.9118 & \\
\hline case1 & 18 & 0.9314 & 2.149 \\
\hline case2 & 18 & 0.9349 & 2.533 \\
\hline case3 & 18 & 0.9349 & 2.533 \\
\hline case4 & 14 & 0.9679 & 6.153 \\
\hline
\end{tabular}

Table 4 shows \% improvements in power loss due to active component of branch current, reactive component of branch current and total active power loss of the system in the four cases considered. 


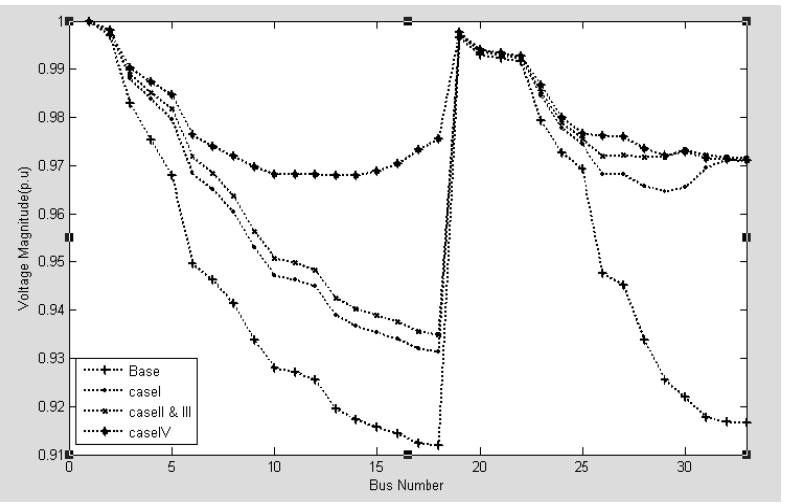

The loss due to active component of branch current is reduced by more than $54 \%$ in least and nearly $80 \%$ at best. Though the aim is reducing the $\mathrm{P}_{\mathrm{La}}$ loss, the $\mathrm{P}_{\mathrm{Lr}}$ loss is also reducing due to improvement in voltage profile. From Table V it is observed that the total real power loss is reduced by $38 \%$ in case 1 and $56 \%$ in case 4 .

The convergence characteristics of the solution of Genetic algorithm for all the four cases are shown in figure 2 .

Table 5 shows the minimum, average, maximum values of total real power loss from 100 trials of Genetic algorithm. The average number of iterations and average CPU time are also shown.

Fig.1:Voltage profile with and without DG placement for all Cases

Table 4 :Loss reduction by DG placement

\begin{tabular}{|c|c|c|c|c|c|c|}
\hline $\begin{array}{c}\text { case } \\
\text { No. }\end{array}$ & $P_{L a}(\mathbf{k W})$ & \% Saving & $P_{L r}(\mathbf{k W})$ & \% Saving & $P_{L t} \mathbf{( k W )}$ & $\begin{array}{c}\% \\
\text { Saving }\end{array}$ \\
\hline $\begin{array}{c}\text { Base } \\
\text { case }\end{array}$ & 136.9836 & ---- & 66.9252 & ---- & 203.9088 & ---- \\
\hline case1 & 62.7085 & 54.22 & 64.3834 & 3.7979 & 127.0919 & 37.45 \\
\hline case2 & 53.6323 & 60.847 & 63.7623 & 4.726 & 117.3946 & 42.43 \\
\hline case3 & 53.5957 & 60.874 & 63.7601 & 4.729 & 117.3558 & 42.45 \\
\hline case4 & 27.7143 & 79.768 & 62.5779 & 6.4957 & 90.292 & 55.72 \\
\hline
\end{tabular}
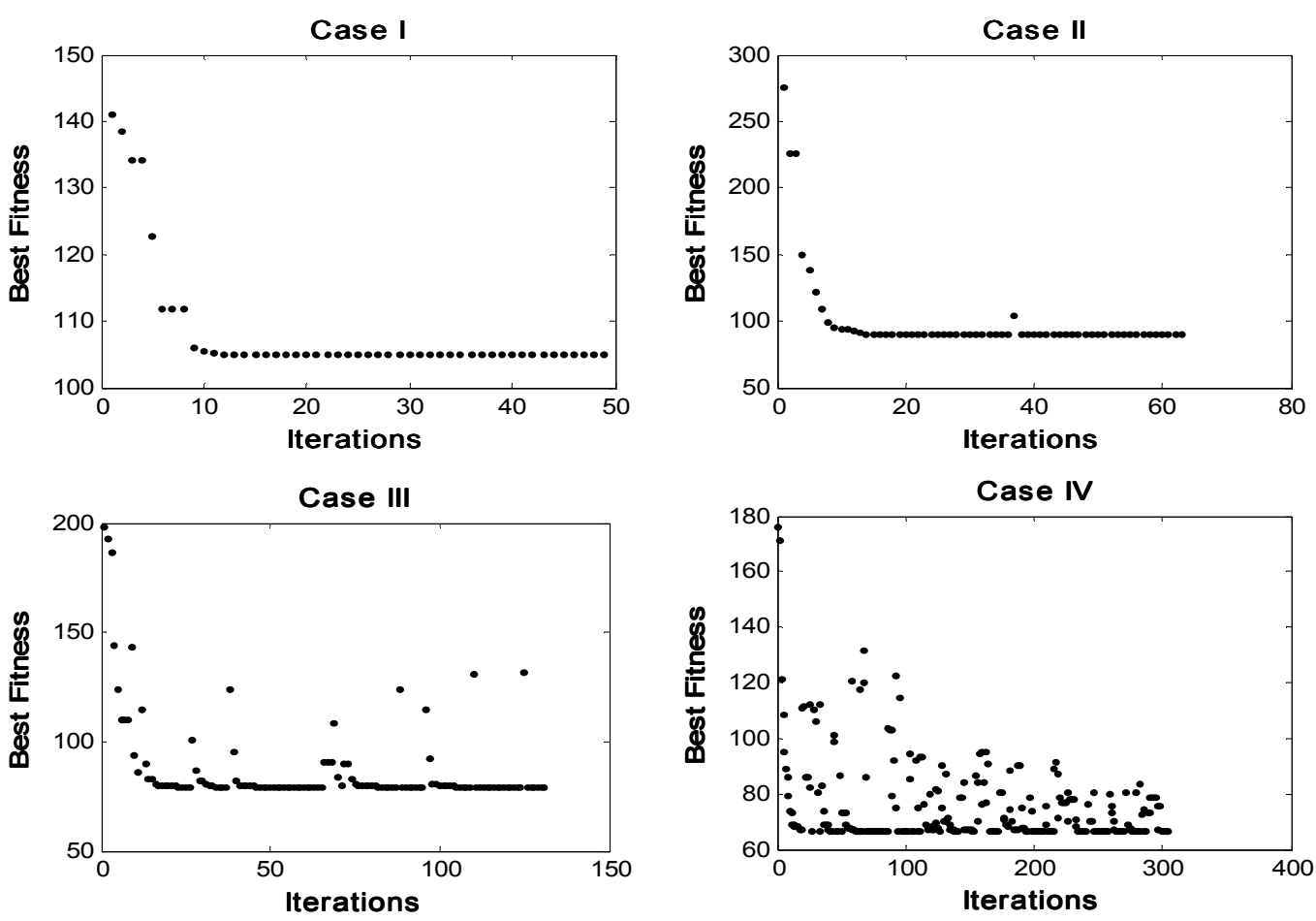

Figure 2: Convergence characteristic of Genetic algorithm for 33 bus test system 
Table 5: Performance of Genetic algorithm for IEEE 33 Bus System

\begin{tabular}{|l|c|c|c|c|}
\hline Total real power loss $(\mathbf{k W})$ & Case I & Case II & Case III & Case IV \\
\hline Min & 105.0231 & 89.9619 & 79.2515 & 66.5892 \\
\hline Average & 105.024 & 89.98 & 81.376 & 68.842 \\
\hline Max & 105.419 & 90.034 & 84.953 & 70.759 \\
\hline No. of Antibodies & 50 & 50 & 50 & 50 \\
\hline Avg. No. of iterations & 49.97 & 63.71 & 131.86 & 319.02 \\
\hline Average Time (Sec.) & 8.703 & 8.844 & 36.563 & 167.265 \\
\hline
\end{tabular}

\subsection{Comparison Performance}

To demonstrate the validity of the proposed method the results of proposed method are compared with an existing Analytical method. The comparison is shown in Table 6. From the table it is clear that the savings by RCGA algorithm are a little higher than the existing analytical method. The reason for this is the increased size of DG units. Table 7 shows comparison of voltage profile improvement by the two methods. The minimum voltage and \% improvement in minimum voltage compared to base case for all the four cases, for the two methods discussed, are shown in this Table. For all the four cases the improvement is better for the second method.

From the above tables it is clear that the results obtained by the GA method and the other method are similar which shows the efficacy of the GA method. And the added advantages of proposed method includes easy incorporation of real time constrains on the system like time varying loads, different type of DG units etc. to effectively apply for real time operation of a system.

Table 6: Comparison of results of IEEE 33-bus system by proposed method and other existing method

\begin{tabular}{|c|c|c|c|c|c|c|c|}
\hline \multirow[t]{2}{*}{ Case } & \multirow{2}{*}{$\begin{array}{c}\text { Bus } \\
\text { locations }\end{array}$} & \multicolumn{2}{|c|}{$\operatorname{sizes}(\mathrm{Mw})$} & \multicolumn{2}{|c|}{ Total Size(Mw) } & \multicolumn{2}{|c|}{ saving $(\mathrm{Kw})$} \\
\hline & & $\mathbf{P M}$ & $\mathbf{A M}$ & $\mathbf{P M}$ & $\mathbf{A M}$ & PM & $\mathbf{A M}$ \\
\hline 1 & 6 & 1.2931 & 1.1883 & 1.2931 & 1.1883 & 76.817 & 76.3619 \\
\hline \multirow{2}{*}{2} & 6 & 0.3836 & 0.3244 & \multirow{2}{*}{1.5342} & \multirow{2}{*}{1.416} & \multirow{2}{*}{86.5142} & \multirow{2}{*}{86.0246} \\
\hline & 15 & 1.1506 & 1.0916 & & & & \\
\hline \multirow{3}{*}{3} & 6 & 0.2701 & 0.2106 & \multirow{3}{*}{1.5342} & \multirow{3}{*}{1.416} & \multirow{3}{*}{86.553} & \multirow{3}{*}{86.0628} \\
\hline & 15 & 1.1138 & 1.0551 & & & & \\
\hline & 25 & 0.1503 & 0.1502 & & & & \\
\hline \multirow{4}{*}{4} & 6 & 0.2701 & 0.2106 & \multirow{4}{*}{1.8423} & \multirow{4}{*}{1.74416} & \multirow{4}{*}{113.6166} & \multirow{4}{*}{112.996} \\
\hline & 15 & 0.8233 & 0.8031 & & & & \\
\hline & 25 & 0.1503 & 0.1502 & & & & \\
\hline & 32 & 0.5986 & 0.5803 & & & & \\
\hline
\end{tabular}

Table 7: Comparison of Voltage improvement by proposed method and other existing method

\begin{tabular}{|c|c|c|c|c|}
\hline \multirow{2}{*}{ Case No. } & \multicolumn{2}{|c|}{ Min Voltage } & \multicolumn{2}{c|}{ \% improvement } \\
\cline { 2 - 5 } & PM & AM & PM & AM \\
\hline Base case & \multicolumn{2}{|c|}{0.9118} & \multicolumn{2}{c|}{} \\
\hline case1 & 0.9314 & 0.9299 & 2.149 & 1.985 \\
\hline case2 & 0.9349 & 0.9333 & 2.533 & 2.358 \\
\hline case3 & 0.9349 & 0.9333 & 2.533 & 2.358 \\
\hline case4 & 0.9679 & 0.9659 & 6.153 & 5.933 \\
\hline
\end{tabular}

\section{CONCLUSIONS}

In this paper, a two-stage methodology of finding the optimal locations and sizes of DGs for maximum loss reduction of radial distribution systems is presented. A single DG placement algorithm is proposed to find the optimal DG locations and a
RCGA method is proposed to find the optimal DG sizes. Voltage and line loading constraints are included in the algorithm.

This methodology is tested on IEEE 33 bus system. By installing DGs at all the potential locations, the total power loss of the system has been reduced drastically and the voltage profile of the system is also improved. Inclusion of the real time constrains 
such as time varying loads and different types of DG units and discrete DG unit sizes into the proposed algorithm is the future scope of this work.

\section{REFERENCES}

[1] G. Celli and F. Pilo, "Optimal distributed generation allocation in MV distribution networks", Power Industry Computer Applications, 2001. Pica 2001. Innovative Computing For Power - Electric Energy Meets The Market. 22nd IEEE Power Engineering Society International Conference, May 2001, pp. 81-86.

[2] P.A. Daly, J. Morrison, "Understanding the potential benefits of distributed generation on power delivery systems," Rural Electric Power Conference, May 2001, pp. A211 -213.

[3] P. Chiradeja, R. Ramakumar, "An approach to quantify the technical benefits of distributed generation" IEEE Trans Energy Conversion, vol. 19, no. 4, pp. 764-773, 2004.

[4] "Kyoto Protocol to the United Nations Framework Convention on climate change". http://unfccc.int/resource/docs/convkp/kpeng.html

[5] R.E. Brown, J. Pan, X. Feng, and K. Koutlev, "Siting distributed generation to defer T\&D expansion," Proc. IEE. Gen, Trans and Dist, vol. 12, pp. 1151- 1159, 1997.

[6] E. Diaz-Dorado, J. Cidras, E. Miguez, "Application of evolutionary algorithms for the planning of urban distribution networks of medium voltage", IEEE Trans. Power Systems, vol. 17, no. 3, pp. 879-884, Aug 2002.

[7] M. Mardaneh, G. B. Gharehpetian, "Siting and sizing of DG units using GA and OPF based technique," TENCON. IEEE Region 10 Conference, vol. 3, pp. 331-334, 21-24, Nov.2004.

[8] Silvestri A.Berizzi, S. Buonanno, "Distributed generation planning using genetic algorithms" Electric Power Engineering, Power Tech Budapest 99, Inter. Conference, pp.257, 1999.

[9] Naresh Acharya, Pukar Mahat, N. Mithulanathan, "An analytical approach for DG allocation in primary distribution network", Electric Power and Energy Systems, vol. 28, pp. 669-678, 2006

[10 G.Celli,E.Ghaini,S.Mocci and F.Pilo, "A multi objective evolutionary algorithm for the sizing and sitting of distributed generation", IEEE Transactions on power systems,vol.20,no.2,pp.750-757,May 2005.

[11] G.Carpinelli,G.Celli, S.Mocci and F.Pilo,"Optimization of embedded sizing and sitting by using a double trade-off method", IEE proceeding on generation, transmission and distribution, vol.152,no.4, pp.503-513, 2005.

[12] C.L.T.Borges and D.M.Falcao, "Optimal distributed generation allocation for reliability,losses and voltage improvement", International journal of power and energy systems,vol.28.no.6,pp.413-420,July 2006.

[13]M. E. Baran and F. F. Wu, " Network reconfiguration in distribution systems for loss reduction and load balancing", IEEE Transactions on Power Delivery, Vol. 4, No 2 Apr 1989, pp. 1401-1407,.

[14]M.Padma Lalitha,V.C.Veera Reddy, N.Usha “Optimal DG placement for maximum loss reduction in radial distribution system" International journal of emerging technologies and applications in engineering, technology and sciences,July 2009.

[15]M.Padma Lalitha,V.C.Veera Reddy, N.Usha "DG placement using Fuzzy for maximum loss reduction in radial distribution system" International journal of computers applications in engineering, technology and sciences, vol1.pp 50-56,Oct2009,

M. Padma Lalitha. is awarded Ph.D for her work "Soft Computing Techniques for optimal DG placement in Radial Distribution System " from S.V.U. in the year 2011 and is a graduate from JNTU, anathapur in Electrical \& Electronics Engineering in the year 1994. Obtained Post graduate degree in PSOC from S.V.U, Tirupathi in the year 2002. Having 14 years of experience in teaching in graduate and post graduate level. Has 11 international journal publications to her credit. Presently working as Professor and HOD of EEE department in AITS, Rajampet. Areas of interest include radial distribution systems, soft computing in power systems, ANN.

V.C.Veera Reddy. Presently working as HOD \& professor in EEE department of S.V.U. College of Engineering, Tirupathi. He was awarded Ph.D for his work "Modeling \& Control of Load frequency using New Optimal Control Strategy " from S.V.U. in the year 1999. Have 28 years of experience in teaching and worked in various levels. Guided a number of research scholars.Attended a number of national \& international conferences. More than 30 journal publications are there for his credit. Areas of interest include Distribution systems, Genetic Algorithms, Fuzzy Systems, ANN.

N.Sivarami Reddy. Presently working as a professor \& HOD in ME department of AITS, Rajampet. He is pursuing Ph.D. Have 18 years of experience in teaching and worked in various levels. Attended a number of national \& international conferences. Areas of interest include flexible manufacturing systems, Meta heuristic search methods, global optimization techniques.

V.Usha Reddy. is pursuing Ph.D and is a graduate from SVU, Tirupathi in Electrical \& Electronics Engineering and obtained Post graduate degree in PSOC from S.V.U, Tirupathi. Presently working as assistant professor in EEE department of S.V.U. College of Engineering, Tirupathi. Areas of interest include Distribution systems, Genetic Algorithms, Fuzzy Systems, ANN and artificial intelligence in power systems, 